\title{
O LUGAR DO DEVER DE CASA NA SALA DE AULA ${ }^{1}$
}

\section{THE PLACE OF HOMEWORK IN THE CLASSROOM ${ }^{2}$}

\author{
Maria Eulina Pessoa de CARVALHO* \\ Conceição dos S. NASCIMENTO** \\ Clotilde M. de PAIVA****
}

Resumo: O dever de casa constitui problemática pouco pesquisada, ausente da formação docente e planejamento pedagógico. Tem implicações familiares e escolares, pressupondo articulação entre tarefas de casa e classe. Sua eficácia na melhoria do aproveitamento escolar tem sido apontada, mas seu lugar no planejamento pedagógico não tem tido atenção. Qual o lugar do dever de casa na sala de aula as práticas docentes atuais? Esta questão é explorada empiricamente em turmas de $4^{\mathrm{a}}$ série do Ensino Fundamental de escolas públicas de João Pessoa, através da observação e entrevistas com professoras. Os resultados indicam que o dever de casa é uma prática rotineira de exercícios individuais de aplicação e fixação, sendo prescrito e corrigido em aula, tomando para isso muito tempo. Articula-se de forma mais ou menos sistemática ou precária ao planejamento pedagógico, segundo um modelo curricular e pedagógico tradicional que requer monitoramento doméstico cotidiano ou desenvolvimento de hábitos de estudo independente, o que não tem obtido sucesso generalizado. Diante do desafio da equidade, considerando que sua produtividade depende das condições familiares e do bom planejamento pedagógico, são urgentes inovações pedagógicas que superem o modele em que o dever de casa é parte intrínseca da aula.

Palavras-chave: Dever de casa. Planejamento pedagógico. Relações família-escola.

Abstract: Homework has not been enough researched, and it has been absent both in teacher education and pedagogical planning. Homework has family as well as school

\footnotetext{
${ }^{1}$ Este trabalho é resultante do projeto de pesquisa Concepções e Práticas de Dever de Casa. Subprojeto: Dever de casa e trabalho docente, PIBIC/DHP/CE/UFPB.

${ }^{2}$ This study is the result of the research project Conceptions and Practices of Homework. Sub-project: Homework and Teaching, PIBIC/DHP/CE/UFPB.

* Professora do Departamento de Habilitações Pedagógicas e do Programa de Pós-Graduação em Educação da Universidade Federal da Paraíba.

** Aluna do Curso de Pedagogia e Bolsista PIBIC da Universidade Federal da Paraíba.

*** Aluna do Curso de Pedagogia e Bolsista PIBIC da Universidade Federal da Paraíba.
}

Olhar de professor, Ponta Grossa, 9(2): 341-357, 2006. 
implications and it presupposes the articulation between homework and the activities done in class. The efficacy of homework in the improvement of students' school development has been pointed out, but its place in pedagogical planning has not received much attention. What is the place of homework in the classroom in current teaching practices? This question has been empirically explored in $4^{\text {th }}$ grades groups of Elementary Education in public state schools in João Pessoa by means of observations and interviews with teachers. The findings indicate that homework is the routine practice of exercises done to practice or reinforce content. Furthermore, homework is corrected in class taking much of class time. Homework is articulated in a somewhat systematic or precarious form with pedagogical planning according to a traditional and pedagogical model which requires home monitoring or the development of independent study habits, which has not been achieved much success. The challenges faced by equity and considering that its productivity depends on family conditions and of good pedagogical planning indicate that pedagogical innovations that overcome the model in which homework is an intrinsic part of the class are needed urgently.

Key words: Homework; Pedagogical Planning; Family-school Relations.

Presente tanto na memória de avós, pais e mães dos alunos e alunas quanto nas salas de aula da atualidade, o dever de casa faz parte da nossa cultura escolar. Reconhecido unanimemente como uma necessidade educacional por educadores e familiares e como uma ocupação adequada para os estudantes em casa, constitui o principal dispositivo de interação escola-família, para usar termo empregado por Bernard Lahire, citado por Nogueira (2005). Todavia, diante de sua importância no coti-diano das salas de aula e dos lares, não tem sido suficientemente proble-matizado em suas concepções e implicações, seja da perspectiva da família, seja do trabalho docente (CARVALHO, 2004b, 2001).

Especificamente, o dever de casa constitui um paradigma curricular e didático que articula a aprendizagem acadêmica em classe e em casa, e se integra direta ou indiretamente ao processo de avaliação. Como estratégia pedagógica tem múltiplas finalidades: estender o tempo de aprendizagem, completar a quantidade de matéria a ser dada numa jornada escolar insuficiente, conectar o trabalho de classe precedente e subseqüente, treinar e reforçar habilidades, estimular hábitos de estudo independente, aplicar os conhecimentos acadêmicos à vida cotidiana, enriquecer o currículo ampliando as experiências de aprendizagem, informar os pais sobre as atividades da escola e conectar escola e família (CARVALHO, 2001). Portanto, é visto como um recurso importante que potencialmente poderia beneficiar todos os estudantes, contudo não é enfocado na formação docente 
ou no planejamento pedagógico (NOGUEIRA, 2002).

Toda escola e todo(a) professor(a) adotam uma política mais ou menos formal/informal de dever de casa com determinados objetivos visando a articular os esforços educativos da escola e da família, a qual, por sua vez, às vezes o valoriza e demanda. Como se sabe, o sucesso escolar conta com a contribuição direta ou ação compensatória da família, bem visível no contexto das escolas particulares, sob duas formas: implicitamente graças à afinidade entre currículo e capital cultural adquirido na socialização primária (educação doméstica) e corporificado no habitus (conjunto de disposições psicossomáticas) do estudante (BOURDIEU, 1986; BOURDIEU \& PASSERON, 1975); ou explicitamente, via dever de casa, capitalizando o tempo e recursos materiais e simbólicos dos pais ou adultos responsáveis, em geral mães, que aderem à função de professor-coadjuvante, ou contratam professores de reforço (CARVALHO, 2001, 2000).

Ao impactar direta ou indiretamente a avaliação, o dever de casa conver-te diferenças familiares de capital econômico, cultural e social (BOURDIEU, 1986) em vantagem ou desvantagem escolar, isto é, em resultados educacionais desiguais, com graves implicações para um projeto de equidade educacional (CARVALHO, 2001). Funciona tanto como política cultural de re-educação de determinadas famílias, limitando sua autonomia ao submeter suas práticas e valores às metas de eficácia escolar e econômica (e penalizando-as quando não atingem as expectativas da escola), quanto como um dispositivo de construção nas crianças do habitus requerido pelo sucesso escolar e pela empre-gabilidade (CARVALHO, 2004a, 2004b).

Embora não seja uma prática regulamentada na escola pública, como se constata nos EUA, o dever de casa faz parte da nossa tradição pedagógica e vem se salientando ultimamente no contexto da política de promoção do sucesso escolar via incentivo à participação da família na escola (CARVALHO, 2001). Paula (2000) constata, na década de 90 , tanto um maior volume de publicações a respeito das tarefas e acompanhamento escolar pela família, quanto uma intensificação de sua prescrição, com ênfase na responsabilidade, autonomia e eficácia. Em 2001, o MEC instituiu o Dia Nacional da Família na Escola e publicou, em 2002, a cartilha Educar é uma tarefa de todos nós. Um guia para a família participar, no dia-adia, da educação de nossas crianças (BRASIL, 2002). As análises dos resultados do SAEB apontaram "o hábito de fazer a lição de casa no rendimento do aluno" (BRASIL, 2003) e a imprensa divulgou: "Acompanhamento familiar eleva nota dos alunos" (FOLHA ONLINE, 2004a). A receita do sucesso escolar inclui os seguintes ingredientes: "a participação dos pais, o interesse da família pela vida 
escolar do aluno, o estímulo à leitura e o hábito de fazer e corrigir o dever de casa" (FOLHA ONLINE, 2004b).

Com base num viés cultural favorável, a pesquisa educacional (que influencia as políticas educacionais) apresenta avaliações positivas da produtividade escolar do dever de casa e recomenda sua adoção (U.S. DEPARTMENT OF EDUCATION, 1987; HENDERSON \& BERLA, 1994; PROJETO NORDESTE, 1997), embora dificilmente se possa estabelecer empírica ou experimentalmente, de forma conclusiva, o impacto positivo do dever de casa no aproveitamento escolar como variável relacionada ao desempenho em testes padronizados. Ademais, sua viabilidade é duvidosa precisamente como incentivo às famílias cujos filhos apresentam baixo aproveitamento escolar, que não dispõem das pré-condições (capital econômico e cultural, organização doméstica favorável e conhecimento acadêmico) requeridas pela prática cotidiana do dever de casa (CARVALHO, 2001). No contexto das escolas públicas que atendem aos estudantes de baixa renda, são corriqueiras as queixas dos (as) professores (as) acerca dos deveres incompletos ou esquecidos pelos alunos e da omissão dos pais.

Além de abrir uma janela nas relações escola-família, o estudo da política-prática do dever de casa possibilita várias abordagens de modelos curriculares, pedagógicos e docentes dependentes da contribuição da famí- lia e da evolução de funções e entrelaçamento das práticas educativas escolares e familiares. Sendo parte do processo ensino-aprendizagem, o dever de casa afeta seu planejamento e, portanto, o trabalho docente, bem como a vida familiar, ao pressupor a conexão entre as atividades de classe e de casa e uma estrutura doméstica de apoio ao aproveitamento escolar (CARVALHO, 2004b). Seja na concepção tradicional de estratégia de intensificação da aprendizagem (exercícios de revisão e fixação), seja numa concepção mais aberta de enriquecimento curricular e conexão dos conteúdos escolares com a vida cotidiana (pesquisas, visitas, utilização de mídias), o dever de casa e justificado como necessário à construção da autonomia e responsabilidade do estudante através do desenvolvimento de hábito de estudo e pontualidade (CARVALHO, 2001).

Se o dever de casa é eficaz para a aprendizagem e sucesso escolar, como apontam o senso comum e as correlações entre adoção/realização e notas do SAEB, em que se baseia sua eficácia? É importante pesquisar concepções e práticas docentes, inclusive formatos adotados. Afinal, qual o lugar do dever de casa no planejamento pedagógico nas práticas docentes atuais? Que explicações os(as) professores(as) apresentam para sua adoção e eficácia? Ora, o dever de casa afeta o planejamento pedagógico, a avaliação, a relação do(a) professor(a) com seus alunos e familiares, e o próprio 
trabalho docente. Integra um modelo docente e pedagógico, pois faz diferença desenvolver o currículo e a aula com ou sem dever de casa. Assim, o rendimento da de classe pode depender mais ou menos da produtividade do dever de casa, conforme o modelo pedagógico adotado, e a efetividade escolar poderia dispensá-lo (CARVALHO, 2001).

Pressupõe-se que a constância do dever de casa comporta variações em conteúdos e formatos, finalidades e significados, modelos de planejamento e avaliação, no tempo e no espaço social e entre diversos tipos de escolas, e também que sua articulação com o trabalho de classe pode revelar facetas interessantes da evolução de concepções e práticas pedagógicas e do trabalho docente. Pressupõe-se, ademais, que sua suposta eficácia depende não apenas da motivação do aluno e apoio familiar, um ponto ressaltado no discurso do (as) professores (as) e formuladores de políticas educacionais, mas do planejamento e prática pedagógica, um ponto silenciado.

Diversas concepções de dever de casa afetam o planejamento pedagógico diferentemente. A prática tradicional como exercícios de fixação e aplicação propiciava ao (à) professor(a) avaliação da aprendizagem e planejamento contínuo do processo pedagógico através da correção diária e minuciosa analise individual, permitindo identificar tipos e extensão das dificuldades dos estudantes e avaliar o desempenho individual e grupal sistematicamente. Além de dar feedback ao estudante e à família sobre seu progresso ou dificuldades, servia principalmente para o (a) professor(a) tratar das dificuldades de aprendizagem, retomando ou avançando conteúdos na aula seguinte.

Transformações curriculares/pedagógicas e a intensificação do trabalho docente, combinada aos baixos salários que obrigam a assumir dois ou três turnos de trabalho, mudaram a forma de avaliação do dever de casa. Os (as) professores (as) já não levam mais os cadernos dos alunos para casa, pois não têm tempo para correção individual, limitando-se a controlar o retorno pontual das tarefas passadas. Atualmente a correção é feita coletivamente em aula, oralmente ou no quadro, com autocorreção pelo estudante. Na pesquisa empírica de Nogueira (2002), realizada em escolas de Goiânia de 1991 a 1995, o tempo dedicado à correção em sala de aula variava de 15 minutos a mais de uma hora. O dever de casa pode até ocupar toda a aula, com a professora revisando o conteúdo do dia anterior, rapidamente apresentando novo conteúdo e passando novo dever (CARVALHO, 2001).

Quanto à ligação com a avaliação formal, na prática tradicional, o dever de casa não valia nota, que era obtida nas provas. A avaliação aparentemente era pontual, mas podia ser realmente formativa, com acompanhamento individual graças à avalia- 
ção informal contínua e sistemática do dever de casa. Atualmente, em contraposição à pressão das provas, e para valorizar o esforço contínuo do estudante, a avaliação vem incluindo o dever de casa, que vale nota ou pontos somados à nota.

Quanto ao planejamento, ao ampliar o tempo de aprendizagem e articular o trabalho adicional desenvolvido fora da aula, o dever de casa aumenta a complexidade do trabalho docente, sobretudo quando se objetiva atender às necessidades específicas ou diferenças individuais dos estudantes (CARVALHO, 2001). Além disso, sua implementação pode requerer instruções aos familiares dentro do que se chama comunicação casa-escola, no contexto do jogo de controles recíprocos entre escola e família acerca do aproveitamento do estudante (FRANCO, 2002).

Para delinear o lugar do dever de casa na prática pedagógica e a articulação entre trabalho de casa e de classe, foram realizadas observações em salas de aula de $4^{\mathrm{a}}$ série de escolas públicas de Ensino Fundamental de João Pessoa, durante uma semana completa, bem como entrevistas com os (as) professores (as). Objetivou-se relatar ainda o tempo gasto com o dever de casa em aula, bem como abordar a prática desenvolvida pelo (a) docente em busca do melhor aproveitamento desse recurso. A descrição e análise dessa abordagem exploratória são apresentadas a seguir.

\section{CASO 1: UMA PRÁTICA DE ENSINO-APRENDIZAGEM BEM ARTICULADA AO PLANE- JAMENTO PEDAGÓGICO}

A observação na turma de $4^{\mathrm{a}}$ série de uma escola municipal de Ensino Fundamental, realizada de 26 a 30/09/ 2005, evidenciou uma prática sistemática de dever de casa articulada ao planejamento pedagógico. A turma tem apenas 12 alunos e alunas, todos de baixa renda, em sua maioria procedentes de uma favela situada atrás da escola, com pais e mães analfabetos, semi-analfabetos, ou ainda alfabetizados mas que não podem dar o acompanhamento necessário aos estudos dos filhos por trabalharem o dia todo.

Como foi verificado, a escola segue os PCNs e busca adequar o currículo à realidade dos alunos a fim de melhorar o aproveitamento escolar. No planejamento pedagógico bimestral, são seguidas as orientações da Secretaria Municipal de Educação es-quematizadas num plano afixado na parede contendo: objetivos gerais, eixo temático, conteúdos e objetivos propostos para cada disciplina. A professora da $4^{a}$ série observada estabeleceu o seguinte plano semanal:

- $2^{\text {a }}$ feira: português (textos), educação física e matemática.

- $3^{\text {a }}$ feira: português (gramática), educação física e ciências.

- $4^{\mathrm{a}}$ feira: português (ortografia), história e educação física. 

fia.

- $5^{\mathrm{a}}$ feira: matemática e geogra-

- $6^{\mathrm{a}}$ feira, educação religiosa, ciências e artes.

Conforme seu depoimento, a professora tenta praticar a interdisciplinaridade no contexto das matérias e assuntos do dia. Nota-se sua preocupação com a prática do dever de casa: sabe da importância deste instrumento, o qual, nas suas palavras, "serve de apoio para que as crianças possam prolongar a aprendizagem". A correção se dá no dia dedicado a cada matéria específica.

Seus alunos e alunas, salvo dois casos, de modo geral fazem os deveres de casa sozinhos; dois alunos são beneficiados pelo reforço escolar oportunizado pela ONG Aldeia S.O.S. e outro tem professora particular em casa. Ressaltou também que a participação dos pais/mães no auxílio das atividades de aprendizagem é mínima ou inexistente.

Considerando que a maioria não obtém auxílio algum, ela não exige que os deveres de casa estejam corretos, mas que sejam feitos. Essa foi a maneira encontrada para estimular sua feitura, porque antes, segundo seu relato, as crianças sentiam vergonha de apresentar os cadernos, por não saberem se tinham respondido o exercício corretamente, e o não cumprimento dessa exigência baixava o rendimento escolar. Isso porque a avaliação nessa escola visa a aspectos quantitativos e qualitativos, correspondendo $50 \%$ ao domínio de con- teúdos (trabalhos individuais e grupais) e $50 \%$ à soma de uma série de fatores: assiduidade, disciplina, ser ativo nas aulas, ter respeito, ser cumpridor dos deveres de classe e casa e manter a organização do material.

Na semana observada, destacase a $2^{\text {a }}$ feira como significativa para os objetivos de pesquisa, por ser o início das atividades semanais e por a aula ter sido iniciada às 13 horas pela correção do dever de casa de português, passado na $4^{\mathrm{a}}$ feira anterior sobre o emprego dos substantivos, verbos e advérbios. A correção foi feita em dois momentos: primeiro, de forma oral, à medida que a professora indagava sobre as questões e os alunos iam respondendo, mantendo-se assim uma interação constante, com a professora tirando as dúvidas e esclarecendo as questões até então não compreendidas; depois ela fez a correção e passou o visto nos cadernos um a um em sua mesa, fato possibilitado pelo tamanho da turma. Todo esse procedimento teve duração de 10 minutos para a correção oral coletiva e aproximadamente 3 minutos para cada caderno, totalizando 45 minutos.

Após a correção do dever de casa, às $13 \mathrm{~h} 45$ a professora retomou o assunto referente a verbos e advérbios e às $14 \mathrm{~h} 10$ aplicou um exercício de revisão, articulando, portanto, o dever de casa ao de classe. Mais uma vez efetivou a correção dos cadernos um a um em sua mesa à medida que os alunos iam terminando, procedimento que se alongou até após a hora 
do lanche e recreio, das $15 \mathrm{~h} 00$ às $15 \mathrm{~h} 30$, entrando no horário da aula seguinte, de educação física, pois algumas crianças só terminaram o exercício após o recreio.

Durante o recreio, a professora foi preparando o que seria visto na última aula do dia, de matemática, e ainda corrigiu alguns cadernos atrasados. Enfatizou a importância das crianças acompanharem o ritmo das aulas entregando as atividades correspondentes ao primeiro horário no primeiro horário, para não atrapalhar o andamento da aula do segundo horário.

A aula de educação física tomou tempo da última aula, portanto ela teve de inverter o plano da aula de matemática, passando assim às $16 \mathrm{~h} 10$ um exercício sobre números racionais como tarefa de casa, antes de dar a explicação do assunto. Isto porque "se agisse de outra forma as crianças ficariam ansiosas ao se aproximar o horário de irem para casa e não teriam paciência para copiar o dever de casa do dia". Após passar a tarefa, às 16h20, explicou então o assunto utilizando dobraduras de uma folha de papel e exposição de figuras referentes a frações no quadro, solicitando a participação da turma.

2 CASO 2: UM RITUAL MAL ARTICULADO AO PROCESSO ENSINO-APRENDIZAGEM

$\mathrm{Na} 4^{\mathrm{a}}$ série de uma escola estadual de Ensino Fundamental, situada em bairro periférico, observou-se que os deveres de casa são a última atividade da aula, dando-se por volta das 10h30, e nem sempre estão ligados ao tema do dia, correspondendo à crítica de Rebelo e Correia (1999, p. 17) de que "são executados apenas como rituais, sem qualquer relação com as atividades que se desenvolvem diariamente", além de serem tarefas uniformizadas, sem considerar os diversos níveis de aprendizagem. A escola não conta com coordenadora pedagógica.

A turma tem 30 alunos e alunas. Numa $3^{a}$ feira, 20/09/2005, a professora começou as atividades às $7 \mathrm{~h} 30$ com uma aula de matemática: divisão de frações. Às 7h45 aplicou um exercício composto de 10 questões sobre o te-ma, cada item valendo um ponto. Avisou que a tarefa teria de ser concluída antes do recreio, sob pena de perdê-lo. Os alunos e alunas executaram a tarefa rapidamente e, em seguida, às $8 \mathrm{~h} 30$, ela passou à aula de português; fizeram uma leitura, cada um lendo um parágrafo de um texto. Logo após a leitura, propôs um exercício: retirar verbos da primeira e da segunda conjugação, palavras no plural, palavras com ss, título, frase que mais gostou. Após a correção oral e coletiva desse exercício, às 9h45, a professora fez ditado de frases como treino ortográfico, corrigindo-o também no quadro. Exatamente às $10 \mathrm{~h} 20$ começou a orientação para o dever de casa: estudar e responder da página 93 a 96 do livro de ciências, cujo tema era energia e ainda pesquisar sobre pla- 
cas de sinalização de trânsito.

No dia seguinte, a aula iniciou sem qualquer referência às tarefas solicitadas no dia anterior. $\mathrm{O}$ conteúdo era novo: aspectos culturais do Brasil. Neste caso, observou-se que os deveres de casa são prescritos sem objetivo explícito relativo ao processo pedagógico que tem lugar na sala de aula.

Quanto à avaliação, notou-se que a tarefa de casa de ciências não foi retomada até o final da semana, podendo ser corrigida na semana seguinte, em alguma aula e horário destinado a ciências. Todavia, pode-se questionar a distância temporal entre a realização do dever de casa e sua revisão.

Um fato interessante a ser destacado foi a ausência de dever de casa no final de semana,pois, segundo a professora "os alunos devem ficar livres e tranqüilos no fim de semana, sem tarefas".

Uma outra observação que comprova a prescrição do dever de casa mal integrado ao planejamento pedagógico e a um processo de ensinoaprendizagem significativo foi realizada numa sala de $3^{\mathrm{a}}$ série da mesma escola, na $3^{\text {a }}$ feira, 02/08/2005, turno da tarde. A professora começou com a aula de ciências, cujo tema era como as plantas se reproduzem, continuando depois do recreio com uma produção de texto sobre o dia do carteiro e finalizando, por volta das $16 \mathrm{~h} 30 \mathrm{com}$ um dever de casa de português, assim descrito: completar palavras com
$\mathbf{S}$ ou $\mathbf{z}$ e pesquisar no dicionário o significado de algumas palavras como lantejoulas, atmosfera, mistério, marmelada, bestagem etc. Que ligação tem esse trabalho de casa com o conteúdo trabalhado em sala de aula? Notou-se também que as atividades da aula não correspondiam ao plano do dia registrado no caderno de planejamento adotado oficialmente pela rede estadual de ensino.

\section{CASO 3: UM INSTRUMENTO DE COMPENSAÇÃO DA BAIXA PRODUTIVIDADE DA AULA}

Numa escola pública municipal de periferia, onde as reuniões mensais de pais e mestres contam com participação reduzida, a turma de $4^{\mathrm{a}}$ série observada tem 32 alunos e alunas, com faixa etária entre 10 e 12 anos. Sua professora atua há 13 anos nessa série e participa do planejamento pedagógico bimensal.

A observação foi realizada entre os dias 6 e 10/03/2006, destacandose a $3^{\text {a }}$ feira como dia significativo, por a aula ter iniciado às $7 \mathrm{~h} 00$ pela correção do dever de casa de português passado no dia anterior, o treino de leitura de um texto. A professora utilizou como estratégia pedagógica a leitura compartilhada: cada aluno lendo um trecho, procurando "fazer com que cada um demonstre a sua capacidade, bem como facilitar o encontro das falhas existentes para tentar corrigi-las a tempo". Em seguida ela demonstrou a forma correta de se ler. 
Este momento se estendeu muito, não só pelas dificuldades das crianças na leitura e compreensão, mas pela falta de disciplina e também pelas péssimas condições acústicas da sala da aula, localizada entre o pátio e a quadra de esportes, donde emanava intenso barulho.

Por não evidenciar melhora na leitura dos alunos, a professora supôs que a leitura antecipada como tarefa de casa não havia sido cumprida; isso, em suas palavras, "comprova a tese de que o dever de casa às vezes deixa algumas lacunas". Ora, como poderia ter havido progresso, neste caso, sem alguém em casa fazendo o mesmo papel que a docente desempenhou em classe? Embora reconhecesse que "muitos deles contam com quase nenhum apoio dos pais para o cumprimento de seu dever de casa, pela total ausência dos pais em quererem ou poderem acompanhar o andamento do filho na escola, por trabalharem ou por não terem o estudo", destacou a falta de atenção, compromisso e responsabilidade dos próprios alunos, pois "a maioria dá qualquer desculpa para não fazer o dever de casa e uma grande parcela deixa seu material em casa, dizendo que esqueceu, para evitar trabalho em classe".

A professora prosseguiu a aula instigando os alunos a interpretarem o texto e compreenderem sua importância. Comentou que o compromisso do aluno não acaba quando termina a leitura do seu trecho, pois para se alcançar a compreensão do que está posto ali, é necessário acompanhar a leitura até o final. $\mathrm{O}$ tema do texto era a amizade e durante a discussão a maioria participou relatando suas próprias experiências, porém, apesar do esforço feito por ela em tentar prender a atenção de todos, sobretudo dos que apresentavam maior dificuldade, houve casos em que se notava total distração e falta de participação.

Essa atividade se estendeu pelo primeiro horário e adentrou o segundo. Para aproveitá-la, a professora resolveu trabalhar palavras do texto que continham encontros consonantais, passando às $9 \mathrm{~h} 00$ um exercício em que os alunos demoraram muito, o que acabou por prejudicar o andamento do planejamento do dia. Às 9h40 saíram para o lanche e recreio. A correção da tarefa de classe foi realizada às $10 \mathrm{~h} 05$, com a professora designando os alunos mais indisciplinados (quase todos meninos) para escreverem a resposta no quadro, os demais foram acompanhando nos cadernos. À medida que acertavam, ela demonstrava sua satisfação, procurando também um modo propício para mostrar a maneira correta àqueles que não haviam acertado.

Por volta de $10 \mathrm{~h} 35$, ela abordou o conteúdo de História (as grandes navegações) através de leitura e discussão de texto, tentando articular com Português ao enfocar a importância dos parágrafos e da pontuação para a construção de textos. Por conta do horário, não pode se estender muito no assunto e anunciou que esse con- 
teúdo de História seria retomado noutro momento.

Às 10h45 iniciou a prescrição dos deveres de casa de História com três questões que abordavam o assunto tratado; de Português, solicitando a identificação e localização do aluno (nome, endereço e telefone) e, novamente, exercícios de encontros consonantais, além da leitura e interpretação de um pequeno texto. Apesar de não se ter estudado matemática nesse dia, ainda passou questões sobre o sistema de numeração decimal e as quatro operações, justificando que esses dois assuntos se constituíam em uma das maiores dificuldades de seu alunado.

Percebeu-se que a professora considerava a manutenção da disciplina a problemática mais importante em sua sala de aula, "senão eles passam por cima da minha autoridade". Para ela, a disciplina é o alicerce para qualquer trabalho pedagógico: "se não for possível manter um clima de ordem, as tarefas de classe ou casa não surtirão efeito e terão ainda mais empecilhos para serem cumpridas". Em geral, sua postura diante dos alunos era coercitiva, reprimindo as interações, exigindo silêncio e utilizando ameaças de perda do recreio e merenda, proibição de ir beber água e ir ao banheiro pelo mau comportamento ou não cumprimento dos deveres. Seu método é o tradicional, de acordo com Luckesi (1994), embora quando entrevistada tenha dito utilizar-se do método construtivista pelo fato de "proporcionar ao aluno um contato direto com a atividade".

Quanto aos alunos, notou-se que à medida que iam realizando suas tarefas de classe queixavam-se da quantidade de deveres passados pela professora, diziam que eram muitos e cansativos, que ela exigia demais deles. Alguns confidenciaram que achavam os deveres de casa muito chatos, que tomavam uma grande parte de seu tempo, alguns eram complicados e nem mesmo com a explicação prévia dada pela professora se tornavam fáceis de resolver. Também mencionaram que não tinham quem os ajudasse e que a tarefa às vezes ia incompleta para a escola, como foi verificado em muitos cadernos. Apesar disso, a maioria faz o dever de casa sozinha, aos "trancos e barrancos", conforme a professora, salvo aqueles que "não têm compromisso com nada!"

\section{CASO 4: PRIMEIRA E ÚLTIMA ATIVIDADE DA JORNADA ES- COLAR}

Na semana de 6 a 10/03/2006 observou-se uma nova turma de $4^{\mathrm{a}}$ série com 23 alunos na mesma escola estadual de periferia do caso 2 . A professora, com 18 anos de magistério, é atenciosa e carinhosa com as crianças, e usa de firmeza quando necessário. Assegura que o dever de casa é fundamental e contribui para a aprendizagem e o desenvolvimento dos alunos, por isso todos os dias passa tarefas para casa, mesmo sabendo que 
muitos não as realizam. Diz ela: "Há quem nunca traz a tarefa respondida alegando não ter tido tempo, que viajou, que esqueceu ou não entendeu..."

No primeiro dia da semana, após rezar o Pai Nosso com seus alunos, convidou-os a abrirem o caderno e procurarem a tarefa de casa de Português que havia sido prescrita na $6^{a}$ feira. Antes de corrigir no quadro, ela vai de carteira em carteira dar o visto, certificando-se de quem fez ou não a tarefa; só então chama os alunos para responderem espontaneamente no quadro. Nesse dia, dos 15 presentes apenas um havia respondido. A tarefa se resumia em ordenar várias frases na ordem dos acontecimentos do texto estudado na $6^{\mathrm{a}}$ feira. Eles consideraram a tarefa difícil e a professora concordou. A correção coletiva no quadro, que começou às $13 \mathrm{~h} 30$, terminou às $14 \mathrm{~h} 10$, levando 40 minutos.

Assim que terminou a correção da tarefa de casa, ela colocou no quadro uma tarefa de classe de Português, contendo cinco questões. Entre copiar e responder, esta atividade ocupou 55 minutos. Em seguida, trabalhou Geografia (formas e representações da Terra, os paralelos e os meridianos, oceanos e continentes) até a hora do recreio às $15 \mathrm{~h} 30$. Assim que retornaram do recreio, às $16 \mathrm{~h} 10$, as crianças foram convidadas a copiar o dever de casa de Geografia que teve quatro questões. Enquanto a apresentação do tema de geografia ocupou apenas 25 minutos, o dever de casa ocupou 35 minutos. Às $16 \mathrm{~h} 45$ come- çou a trabalhar matemática (sistema de numeração decimal), mas não houve tempo suficiente para terminar.

No dia seguinte, logo após o ritual de oração, a professora retomou o conteúdo de matemática e a partir das 13 h30 começou a correção do dever de casa de geografia do dia anterior. Como sempre, antes da correção coletiva, passou em todas as carteiras para verificar quantos fizeram a tarefa, isto porque, segundo ela, alguns aproveitam para responder somente na hora da correção. Dos 17 alunos que estavam na sala, 15 responderam a tarefa, exatamente os que estavam presentes no dia anterior. A professora ressaltou: "quando a tarefa é retirada do quadro geralmente a maioria faz; e quando a tarefa é do livro ninguém faz". A correção foi interrompida às $13 \mathrm{~h} 40$ pelo professor de Educação Física que trabalhou com as crianças até as $14 \mathrm{~h} 30$, hora em que a professora retomou a correção que terminou às $14 \mathrm{~h} 50$, assim, o processo levou 30 minutos.

A professora prosseguiu com a aula de português até as $15 \mathrm{~h} 30$, hora do recreio. Após, passou uma tarefa de classe e assim que terminou, por volta das 16h50, disse: "vamos fazer o dever de casa". As crianças reagiram: "não vai dar tempo", pois só faltavam 10 minutos para o término da aula. Mas a professora respondeu: “dá sim, copiem!". E assim passou uma pequena tarefa de matemática, apenas duas questões: contas de adição e divisão, identificação dos termos da di- 
visão.

No dia 8 de março a professora iniciou dizendo: "Hoje é o dia da mulher, por isso antes da correção do dever de casa eu quero que vocês façam uma redação sobre a mulher e depois ilustrem com gravuras. Aqui estão as revistas". Nesse dia, as 18 crianças presentes escreveram espontaneamente o que achavam da mulher até as $14 \mathrm{~h} 50$. Começou então a correção do dever de casa até as $15 \mathrm{~h} 07$, com algumas crianças indo ao quadro resolver as contas de matemática, durando 17 minutos. Até o recreio a professora prosseguiu com o conteúdo de geografia. O recreio terminou às $16 \mathrm{~h} 15$ e a prescrição do dever de casa de geografia teve início às $16 \mathrm{~h} 30$, indo até as $16 \mathrm{~h} 50$. Foram cinco questões de geografia e também a $1^{a}$ questão da página 18 do livro de matemática. Já no finalzinho da aula ela entregou o desenho de uma mulher para as crianças pintarem em casa.

No dia 9 não foi possível observar, devido à paralisação nas escolas estaduais. No dia 10 a aula começou às $13 \mathrm{~h} 30$, com atraso, tendo apenas 12 alunos presentes. A professora iniciou com História (como viviam os indígenas), e, por motivo de doença, liberou as crianças às $15 \mathrm{~h}$, por isso não houve tempo de corrigir nem passar dever de casa.

Apesar da semana incompleta, notou-se que a prática do dever de casa é sistemática e tem lugar privilegiado em sala de aula, ocupando bas- tante tempo: a correção é a primeira atividade do dia e a prescrição a última. Considerando-se os atrasos no início das aulas e o recreio, o tempo para o desenvolvimento do conteúdo novo em aula é restrito. Observou-se também que se depois do recreio ainda tiver conteúdo para ministrar, a professora passa primeiro o dever de casa para não correr o risco de não sobrar tempo para o mesmo. Depois do recreio as crianças perguntam: "E o dever, tia?"

\section{O LUGAR DO DEVER DE CASA NA SALA DE AULA}

As observações indicam que o dever de casa está presente no cotidiano da sala de aula, em momentos de prescrição e correção, sendo mais ou menos articulado ao trabalho de classe e ocupando tempo variável, o que sugere flexibilidade e adaptação às circunstâncias do dia. Corroboram para integrar um modelo curricular e pedagógico que pretende estender o tempo de aprendizagem além da jornada escolar e ocupar o aluno rotineiramente em casa com tarefas de aplicação e fixação, que são cobradas e avaliadas em aula de várias maneiras: ora massivamente, a correção coletiva com fins pedagógicos (avaliação formativa); ora individualmente, o visto no caderno com fins de controle (avaliação somativa).

Nesse modelo curricular de conteúdos segmentados - apesar de eventuais tentativas de interdisci- 
plinaridade - as tarefas de casa se intercalam às de classe de forma mais ou menos integrada e próxima: ou a aula começa com a correção do dever de casa anterior e termina pela prescrição do dever de casa seguinte, variando o intervalo de tempo entre prescrição e correção; ou a aula termina com a prescrição de tarefas de casa desconectadas das matérias ou conteúdos do dia, faltando con- tinuidade imediata entre trabalho de classe e de casa. Em todo caso, o dever de casa ocupa tempo significativo da aula, como se pode ver no quadro abaixo, variando de 17 a $64 \%$ do total de 210 minutos, considerandose a jornada escolar de quatro horas e o período de lanche e recreio de meia hora. Boa parte desse tempo, seja na prescrição ou correção, é consumido em cópia.

\begin{tabular}{l|c|c|c|c|c|c}
\hline $\begin{array}{l}\text { Tempo do } \\
\text { dever de } \\
\text { casa em } \\
\text { aula }\end{array}$ & Caso 1 & Caso 2 & Caso 3 & $\begin{array}{c}\text { Caso 4 } \\
1 \text { o dia }^{2}\end{array}$ & $\begin{array}{c}\text { Caso 4 } \\
2^{\circ} d i a\end{array}$ & $\begin{array}{c}\text { Caso 4 } \\
3^{\circ} d i a\end{array}$ \\
\hline Correção & $00: 45$ & - & $02: 15$ & $00: 40$ & $00: 30$ & $00: 17$ \\
\hline Prescrição & $00: 10$ & $00: 40$ & - & $00: 35$ & $00: 10$ & $00: 20$ \\
\hline Total & $00: 55$ & $00: 40$ & $02: 15$ & $01: 15$ & $00: 40$ & $00: 37$ \\
\hline
\end{tabular}

Ora, nesse modelo, baseado nos passos formais de Herbart, o dever de casa tem duas justificativas principais: estender o tempo de aprendizagem e desenvolver a autono-mia do estudante, torná-lo sujeito do próprio processo de aprendizagem (NOGUEIRA, 2002; CARVALHO, 2001). Assim, como continuação da aula, o dever de casa depende de motivação e disciplina dos estudantes e deve ser planejado de modo a favorecê-las, possibilitando a conexão de experiências e aprendizagens em tempos e espaços distintos, escolares e domésticos. Portanto, deve ser exequiível, suficientemente curto e fá- cil, e quiçá prazeroso e criativo (NOGUEIRA, 2002). Todavia, as observações relatadas indicam que a prática do dever de casa pode integrar o processo pedagógico de forma mais ou menos sistemática, significativa para os alunos e efetiva em termos de aprendizagem, o que significa dizer que o velho modelo Herbartiano nem sempre é bem utilizado.

Ao se escolher a $4^{\mathrm{a}}$ série, supôsse que alunos e alunas são mais velhos, mais independentes e já estão habituados à prática da tarefa de casa a esta altura de sua escolaridade. Mesmo assim, conforme as professoras, eles/elas nem sempre se compro- 
metem com o dever da casa, portanto esta prática não tem sido bem sucedida em favorecer a autonomia gradual de todos os estudantes. Segundo uma delas (caso 4), é mais freqüente a realização da tarefa quando copiada do quadro do que quando indicada no livro, o que sugere que ao copiar e, de certa forma, iniciar a tarefa em classe o aluno não esquece, se motiva e se compromete.

Para consolidar-se como prática rotineira, o dever de casa era passado no final da jornada escolar de um dia para ser retomado no início do outro. Porém, como observado, nem sempre a tarefa de casa é uma continuação ou complementação do trabalho de classe do dia. O modelo curricular e pedagógico segmentado em várias matérias/horários por dia exige planejamento do dever de casa pelo aluno e/ ou por quem o acompanha em casa. Assim, observa-se no caso 1, em que o dever de casa é bem articulado ao planejamento pedagógico, que a tarefa de português passada numa $4^{\mathrm{a}}$ feira será avaliada somente na $2^{\mathrm{a}}$ feira seguinte; a tarefa de matemática passada na $2^{\mathrm{a}}$ feira será corrigida na $5^{\text {a }}$ feira e a de ciências passada na $3^{\mathrm{a}}$ feira será corrigida na $6^{\text {a }}$ feira; os deveres de história, geografia, educação religiosa e artes, se adotados, serão avaliados uma semana depois no dia da respectiva aula. Isso, por um lado, acarreta dispersão e, por outro lado, exige organização e disciplina dos alunos que devem seguir à risca a agenda semanal. Provavelmente com esse intuito, em 2006, pela primeira vez o sistema escolar municipal de João Pessoa distribuiu uma agenda do estudante, que visa à comunicação escola-família e à articulação trabalho de classe-trabalho de casa. Se bem utilizada, será um recurso para a construção do habitus de estudante.

Como argumentam Rebelo e Correia (1999) e Nogueira (2002), muitas mudanças ocorreram no campo edu-cativo, mas os deveres de casa continuam sem muitos questionamentos. São exercícios realizados individualmente requerendo dos alunos e alunas o desenvolvimento de hábitos de estudo independente, um modelo que exigiria do (a) professor(a) também a correção individualizada, o que não é mais viável nas atuais condições de trabalho docente. Esta constatação remete à eficácia dos deveres de casa à contribuição da família no seu moni-toramento cotidiano, como reconhecem as professoras, ou à mudança de paradigma pedagógico - a superação definitiva da pedagogia da cópia.

Diante do desafio da equidade educacional, considerando-se que a produtividade do dever de casa é variável conforme as condições familiares dos alunos e o modelo pedagógico adotado pela escola e pela professora, na falta de um bom planejamento pedagógico o dever de casa não pode incrementar a aprendizagem e o aproveitamento escolar. Assim, são urgentes inovações pedagógicas que integrem experiências significativas e 
intensifiquem as aprendizagens na sala de aula em prol da efetividade escolar. Qual seria o lugar do dever de casa numa pedagogia de projetos?

\section{REFERÊNCIAS}

BOURDIEU, P. The forms of capital. In: RICHARDSON, J. G. (Ed.). Handbook of theory and research for the sociology of education. New York, US: Greenwood Press, 1986. p. 241-258.

; PASSERON, J. C. A reprodução: elementos para uma teoria do sistema de ensino. Rio de Janeiro: Francisco Alves, 1975.

BRASIL. Ministério da Educação. Instituto Nacional de Estudos e Pesquisas Educacionais - INEP. Notícias do SAEB. Disponível em: < http://www.inep. gov.br >. Acesso em: 7 jul. 2003.

. Ministério da Educação. Secretaria de Educação Fundamental - SEF. Educar é uma tarefa de todos nós: um guia para a família participar, no dia-adia, da educação de nossas crianças. Brasília: Secretaria de Ensino Fundamental, 2002.

CARVALHO, M. E. P. Modos de educação, gênero e relações escola-família. Cadernos de Pesquisa, São Paulo, v. 34, n. 121, p. 41-58, jan./abr. 2004a.

. Escola como extensão da família ou família como extensão da escola? O dever de casa e as relações família-escola. Revista Brasileira de Educação, $n$. 25, p. 94-104, jan.-abr. 2004b.

Family-school relations: a critique of parental involvement in schooling. Mahwah, US: LEA, 2001.

. Relações entre família e escola e suas implicações de gênero. Cadernos de Pesquisa, São Paulo, n. 110, p. 143-155, jul. 2000.

PROJETO Nordeste. Chamada à ação: combatendo o fracasso escolar no Nordeste: programa de pesquisa e operacionalização de políticas educacionais. 2. ed. Brasília: UNICEF, 1997.

FOLHA Online Educação. Acompanhamento familiar eleva nota dos alunos. Disponível em: < http:// www1.folha.uol.com.br/folha/educacao/ ult305u15831.shtml >. Acesso em: 27 jul. 2004a.

Escola pública boa deve começar em casa. Disponível em: < http:// www1.folha.uol.com.br/folha/educacao/ ult305u15858.shtml >. Acesso em: 1 ago. 2004b.

FRANCO, M. O. C. M. Práticas familiares em relação ao dever de casa: um estudo junto às camadas médias de Belo Horizonte. Dissertação (Mestrado em Educação) - Universidade Federal de Minas Gerais, Belo Horizonte, 2002.

HENDERSON, A.; BERLA, N. (Eds.). A new generation of evidence: The family is crucial to student achievement. Washington, US: National Committee for Citizens in Education, 1994.

LUCKESI, C. C. Filosofia da educação. São Paulo: Cortez, 1994.

NOGUEIRA, M. A. Família e escola na contemporaneidade: os meandros de uma relação. In: REUNIÃO ANUAL DA ANPED, 28, 2005, Caxambu, MG. Anais... Disponível em: < http:// www.anped.org.br $>$. Acesso em: 2 ago. 2006.

NOGUEIRA, M. G. Tarefa de casa: uma violência consentida? São Paulo: Loyola, 
2002.

PAULA, F. A. Lições, deveres, tarefa, para casa: novas e velhas prescrições para professoras. Dissertação (Mestrado em Educação) - Universidade Estadual de Campinas, Campinas, 2000.

REBELO, J. A. S.. CORREIA, O. N. O. N. O sentido dos deveres para casa. Coimbra, Pt: Coimbra, 1999.

UNITED STATES OF AMERICA. Department of Education. What works: research about teaching and learning. Washington, US, 1987.

Enviado em: 02/10/06

Aceito em: 19/10/06 